\title{
Developing A Socio-Spatial Index Methodology for Measuring Cross-Border Mobility
}

\author{
Emrah Söylemez ${ }^{\mathrm{A}^{*}}$, Çiğdem Varol ${ }^{\mathrm{B}}$ \\ Received: October 29, 2019 | Revised: December 29, 2019 | Accepted: December 30, 2019 \\ doi: 10.5937/gp24-23805
}

\begin{abstract}
The article proposes a cross-border mobility model for borderlands by developing a multivariate sociospatial index. Existing methods of evaluating cross-border mobility tend to focus simply on physical and security dimensions of the state borders. However, because of the complex dynamics of relationships among the countries, a multidimensional approach including the economic, social, administrative and spatial relationships have to be considered holistically. The proposed cross-border mobility modeling and index methodology includes spatial and non-spatial multivariate data for assessing the permeability of state borders by using fuzzy logic methods. GIS techniques are used to combine economic, social, administrative and spatial dimensions of relationships for creating the multivariate socio-spatial index and to visualize the results. The results of the proposed methodology experienced for the borderlands of Turkey show that measuring the degree of cross-border mobility can improve the understanding of relationships among the states for developing more effective cross-border policies.
\end{abstract}

Keywords: cross-border mobility; multivariate index; socio-spatial data; fuzzy membership

\section{Introduction}

Composite index construction is a technique to integrate large amounts of heterogeneous data in a compact way (Santeramo, 2016). This provides a comparison of complex issues in multifarious fields such as engineering, geography, environment and economy (Cherchye et al., 2006). Measurement of multidimensional issues of the social, cultural, political, economic, spatial and so forth ought to be represented by different measurements instead of by single descriptive indicators (Lun et al., 2006, Bandura \& Campo, 2006). As having a multinational and socio-spatial content, border mobility becomes a multidimensional issue in terms of concept, data and scope. In analytical studies, borders are mostly discussed more or less subjectively i.e. white-gray-black, and in a narrower scope regarding specific areas or regions (Zartman, 2010;
Popescu, 2006). In various studies, different methods and approaches have been developed for cross-border mobility and permeability (Star \& Thomas, 2002; Stephenne \& Pesaresi, 2006; Hisakawa et al., 2013) due to the availability of data. These approaches are limited in terms of producing a generalizable model due to low diversity in the data sets they use. Thus, there has not been a holistic framework for measuring the mobility considering socio-spatial characteristics of the border region in a multivariate context. Thus, analysis needs to be reconsidered in a broader and multi-dimensional way that will help nation states to make rational and effective decisions and to designate border policies due to cross-border mobility model.

In literature, state borders are mostly defined as bridges, barriers or action spaces. The use of cross-

\footnotetext{
A Ministry of Environment and Urbanization, Mustafa Kemal Mahallesi Dumlupınar Blv. No:278, 06510, Çankaya, Ankara, Turkey, e-mail: emrahsoylemez@gmail.com, ORCID: http://orcid.org/0000-0003-4150-3184

B Department of City and Regional Planning, Gazi University, Eti Mahallesi, Yükseliş Sk. No:5, 06570, Çankaya, Ankara, Turkey, e-mail: cvarol@gazi.edu.tr, ORCID: http://orcid.org/0000-0002-2432-5745

* Corresponding author: Emrah Söylemez; e-mail: emrahsoylemez@gmail.com
} 
border mobility approach in the analyses conducted at national or supranational borders has come to the fore mainly in the context of sovereignty and border security (Dodson, 2000; Missbach, 2014; Stephenne \& Pesaresi, 2006). In political border management context, mainly related to territoriality (Anderson, 2001), "space" dimension has been added to the analyses regarding the control of border space and the movements inside the border regions (Sack, 1986). Other approaches, using economic (O'Dowd, 2002) and geographical indicators (Star \& Thomas, 2002) have considered border as physical boundaries. In this study, cross-border mobility refers to a multivariate and multi-dimensional context including economic, social, administrative and spatial interactions in the border regions. In order to measure cross-border mobility in a multivariate and multi-dimensional context, different evaluation methods can be developed (Starr \& Thomas, 2001; Stephenne \& Pesaresi, 2006; Kolejka et al., 2015; Hisakawa et al., 2013). Based on geographical data, Starr \& Thomas (2001) present a framework that illustrates the relationship between the EU's process-based permeable boundaries and the integration process using different vector and raster datasets, such as the ease of interaction or border detection of the areas requiring security measures. Stephenne and Pesaresi (2006) develop a permeability model that utilizes accessibility, concealment and security indicators by emphasizing geographic permeability. In addition to these studies, the latest mod- els are characterized by the use of GIS technologies. Hisakawa et al. (2013) measure porosity of state borders by using the geographical and physical data along with geocomputational methods.

Existing methodologies have carried out analyses focusing attention on specific aspects of the interactions on border regions. However, in order to comprehend the complex socio-spatial structure of border regions, a holistic perspective is needed that will integrate the tools of present models and the complex socio-spatial components of the border regions. In the face of these considerations, this paper develops a cross-border mobility model for measuring the interactions at state borders, considering socio-spatial characteristics of both sides of the neighboring countries. The proposed model aims to contribute to the research field mainly in two dimensions. Firstly, it presents an initiating framework with its multi-dimensional approach regarding the complexity of border regions. Secondly, concerning the blurred nature of border regions, it integrates fuzzy logic into the combined index methodology. Within this framework the paper starts with conceptual explanations as a basis for the model. Then, it proposes a multivariate socio-spatial mobility index for borders integrating economic, social, administrative and spatial data. The application of the model to Turkish and its neighboring state borderlands helps to find out the cross-border interaction level that will develop effective and unique public policies based on help to the multivariate border mobility levels.

\section{Developing the Socio-Spatial Index and the Cross-Border Mobility Model}

In cross-border interaction analysis, cross-border mobility is the main determining function, which differentiates due to the nature of the border and requires analyses at different scales. Context-dependent variation of mobility definitions in literature is related to the conceptual framework being displayed academically. Within this process, border interaction has generally been reconceptualized by security-based issues (Anderson \& O’Dowd, 1999:597), as well as social, economic and spatial (geography-based) interaction discussions. Security-based approach is a form of political cross-border management and this military defense based perspective on the border is characterized by the fact that central governments ignore the social and economic dimensions among neighboring countries by seeing the border basically politically and militarily (Anderson \& O’Dowd, 1999). Physical barriers and control points are designed as basic tools in security-based analysis. On the other side, social and economic interaction analysis prioritizes economic and social relations and features that consid- er the formal and informal relationships occurring among the neighboring countries. Lastly, geographic-based spatial analysis includes more analytical elements when compared to the other two approaches. It measures geographic permeability by using digital maps and measurable physical and geographical data. These three approaches have unique and differentiated analysis that measure mobility due to their objectives, but they do not provide a holistic model for nation states cross-border mobility (Stephenne \& Pesaresi, 2006; Starr \& Thomas, 2001).

In the production of cross-border mobility model and the multivariate social-spatial index, these concepts are redefined both by physical features and by an overarching content that includes spatial, social, cultural, economic, administrative and security related issues. In order to analyze the cross-border mobility of state borders, first of all, it is necessary to determine what is passing through the borders, how they pass, and what is being filtered. For determining these, concrete variables have to be defined primar- 
ily. In theoretical and empirical studies, cross-border mobility has been considered as the total probability of the transition of goods, capital, information, and people to the other side of the national boundaries. While the measurement of flows is more quantitative, the measurement of mobility is more complex as the content of permeability can change over time by the restrictive and facilitative factors or by national policies. While constraints can be spatial and political barriers, as well as socio-cultural diversity, facilitators can be government supported policies, provided incentives and quality of infrastructure.

Redefining the cross-border mobility concept by a multivariate analysis of economic, social, administra- tive and spatial variables causes a more generalizable and widened geographical context that help to understand the level of relationships among the neighboring countries. The proposed cross-border mobility index created by different variables provides an opportunity to identify the current situation and display the potentials for the convergence of cross-border regions. Created by objective indicators of economic, social, administrative and spatial interaction levels along national boundaries, the proposed GIS-based multivariate cross-border mobility modeling forms the basis for the empirical study of Turkish national land borders.

the border not only as spatial passages but as an integration of political, socio-spatial, socio-cultural and economic interactions. Figure 1 demonstrates the adaptation of composite index methodology to the proposed model.

Two key steps have been established for the development of the index. The first is the creation of data sets and indicators, and the second is the determination of the geographical scope. Based on literature, 22 theoretically and practically important and relevant variables, measuring the flows among countries were chosen to ensure a multidimensional approach in understanding the complexity of the border region. The proposed model was developed by using compiled and computed variables to measure the socio-spatial cross-border mobility model perceives and analyzes

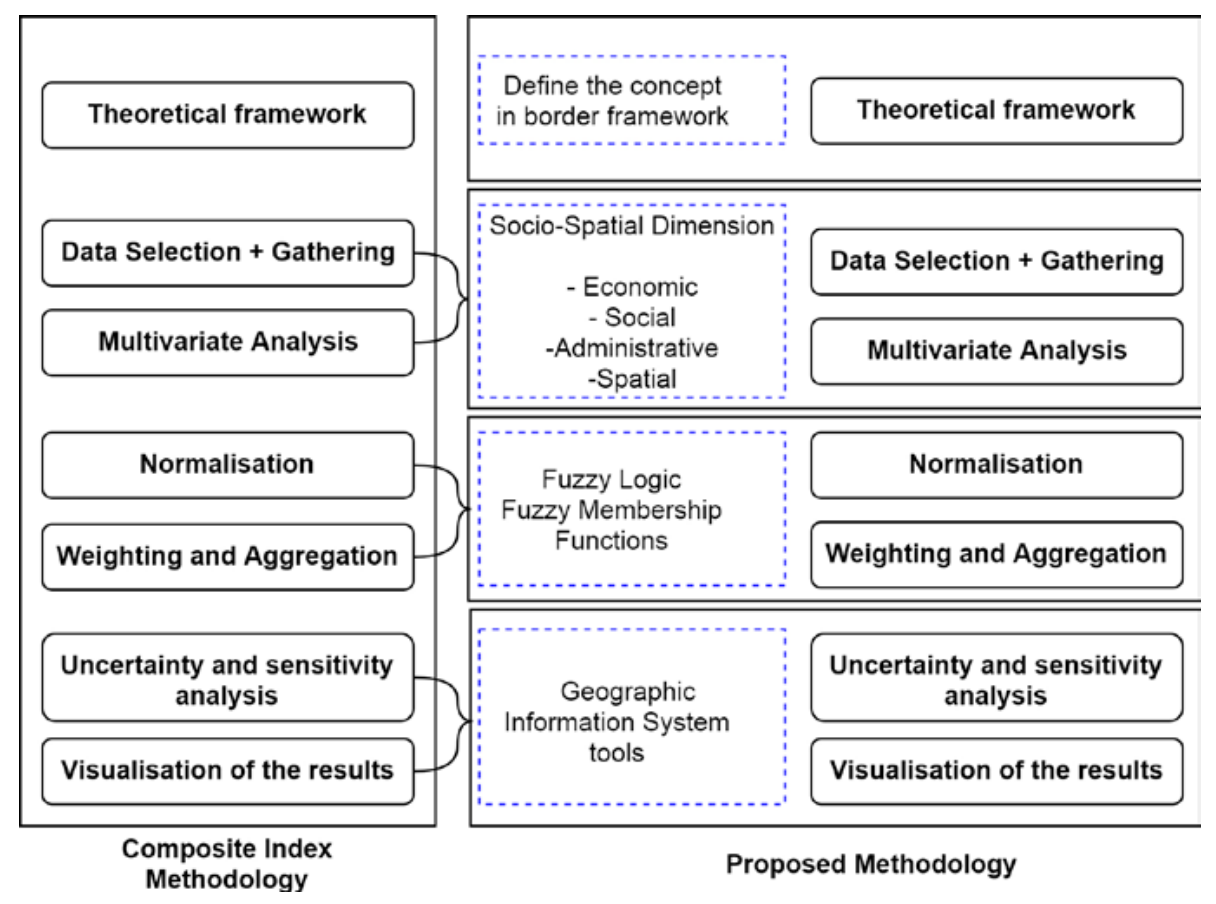

Figure 1. Composite index methodology and proposed model 


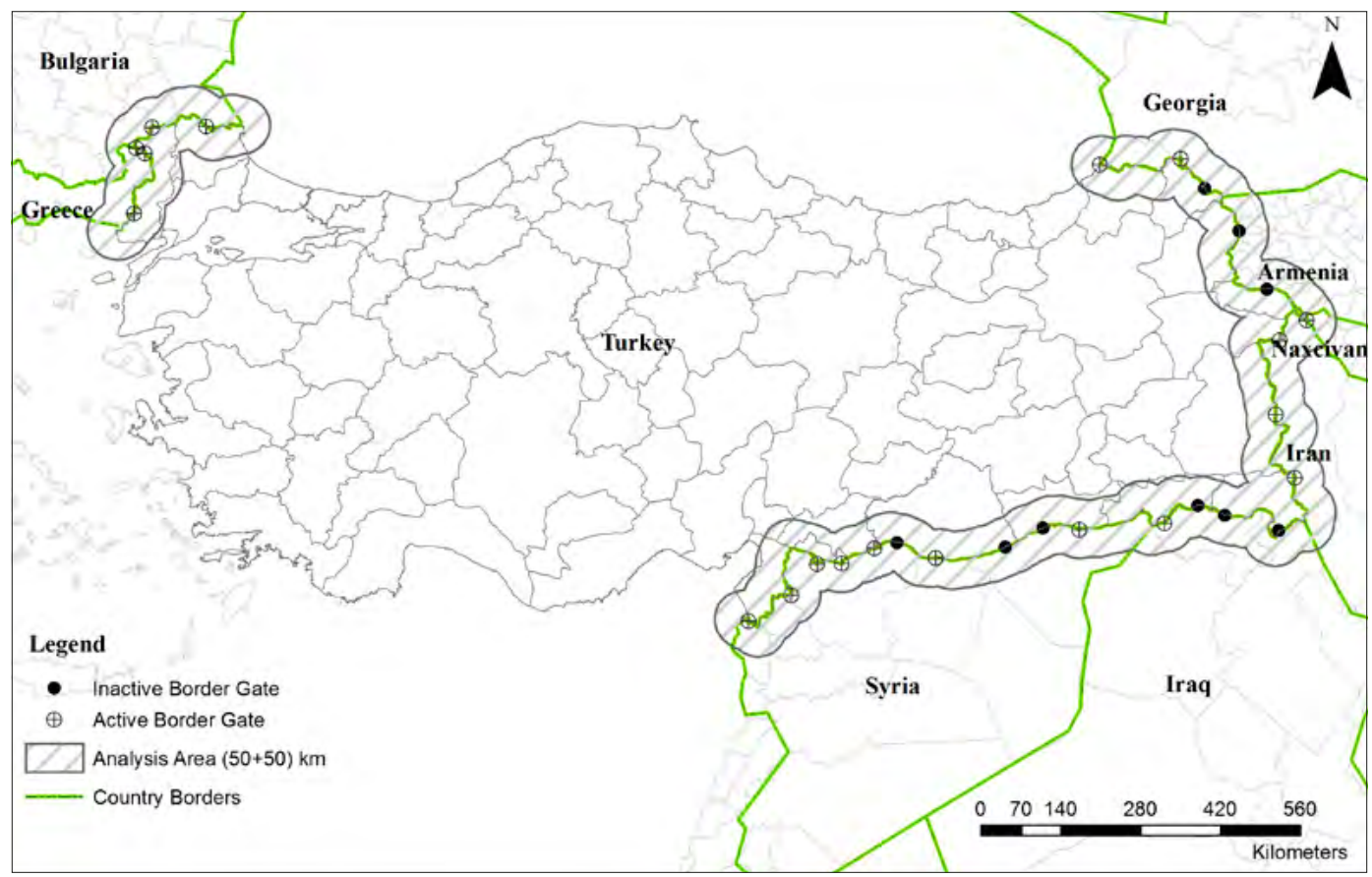

Figure 2. Analysis area and the border gates

interaction in an area of $50 \mathrm{~km}$ buffer of the borderline for both sides (Figure 2). In the related literature (Perkmann, 2002, Stephenne \& Pesaresi, 2006), the boundary depth for defining the border regions vary between 50 to $100 \mathrm{~km}$ where most of the social, economic, administrative and spatial interactions along the border occur. Publicly available data were gathered from different data sources like the Turkish Statistical Institute, General Directorate of Security, Turkish Military Services, several ministries at national level, and local government authorities. In order to minimize the impact of refugee mobility caused by Syrian civil war, 2013 and 2014 data were used.

\section{Defining Subindex Groups for Cross-Border Mobility Indicators}

For creating multidimensional indices, it was necessary to separate the variables into subgroups, which would increase the robustness of the conceptual framework and clarify the set of indicators. It would also improve the user's understanding of driving forces behind the index and would determine the relative weights across different factors (Nardo et al., 2005). Thus, mobility indicators for the study were separated into four subgroups: economic, social, administrative and spatial.

Together with the trade flows between countries, the factors related to the level of correspondence, trade ability and volume, easiness and potential of the economic relationships were assessed as economic mobility in the first subindex group. The indicators discussed by several studies in cross-border economic and regional integration literature were adapted to determine the levels of economic relations (Obstfeld \& Rogoff 2001; Nitsch, 2000; Evans, 2003). Thereby, trade volume by countries, total passenger volume crossing the border, amount of multinational capital investment, direct foreign investment in the border regions, foreign trade balance, border gate types according to customs characteristics, commercial trade quotas for cities located in borderlands, and distance of borderlands to free economic zones were used as economic indicators.

The second subindex group comprises social mobility indicators that try to reveal the possibility of social interaction levels. In this context, religious and sectarian differences and similarities in the border region and the similarities of nationality and historical backgrounds that would help to reveal the dimensions of social permeability were considered. The race/ethnicity structure, religious and sectarian similarities and differences (Izady, 2008a; Izady, 2008b; Meirav, 2011, Luo et al., 2016), social and cultural service volume and population, and settlement densities within $50 \mathrm{~km}$ and $100 \mathrm{~km}$ depth of the borderline were examined.

The third subindex group was defined for administrative mobility. Indicators in this group determined by national or supranational arrangements were mostly put into practice by central governments. Administrative mobility covered the entire border control mechanism on the borders between the two countries. In this framework, visa arrangements which were determined by central governments and considered as indicators of the ease of transition to the other side and visa restrictions by a destination country for 
citizens reduce cross-border flows by \%20 (Czaika and Neumayer, 2017), number of illegal transit attempts at the border, number of smuggling incidents at the border, characteristics of the customs gates, and number and type of sister cities that could coincide with political proximity were taken into consideration.

The fourth subindex group was spatial indicators that had the highest potential to be measured analytically. These were natural thresholds (streams, lakes, etc.), artificial thresholds created by security concerns and making the border less permeable, number of settlements and their densities, average transportation time among the cities on both sides of the border, and road and railway transportation infrastructures.

As composite index validity depends on the strategic objectives of the research (Mazziotta \& Pareto, 2013), variables reflecting the flows among countries were chosen to ensure a multidimensional approach in understanding the complexity of the border region. After subgrouping the main index components and related variables, all economic, social, administrative and spatial data in tabular form were analyzed in Geographic Information Systems Software (ArcMap) in order to realize necessary steps for achieving multivariate socio-spatial cross-border mobility index for border regions (Figure 3).

The data for Turkish borderlands consisted of a spatially referenced longitudinal database that included nearly $3300 \mathrm{~km}$ long and $100 \mathrm{~km}$ wide area with 16 million population for the year 2013. The borderland was divided into $10 \times 10 \mathrm{~km}$ grids that consisted of 343 grids in total. Four subgroups of variables were rasterized before applying fuzzy classification methods that were used for the standardization of each layer.

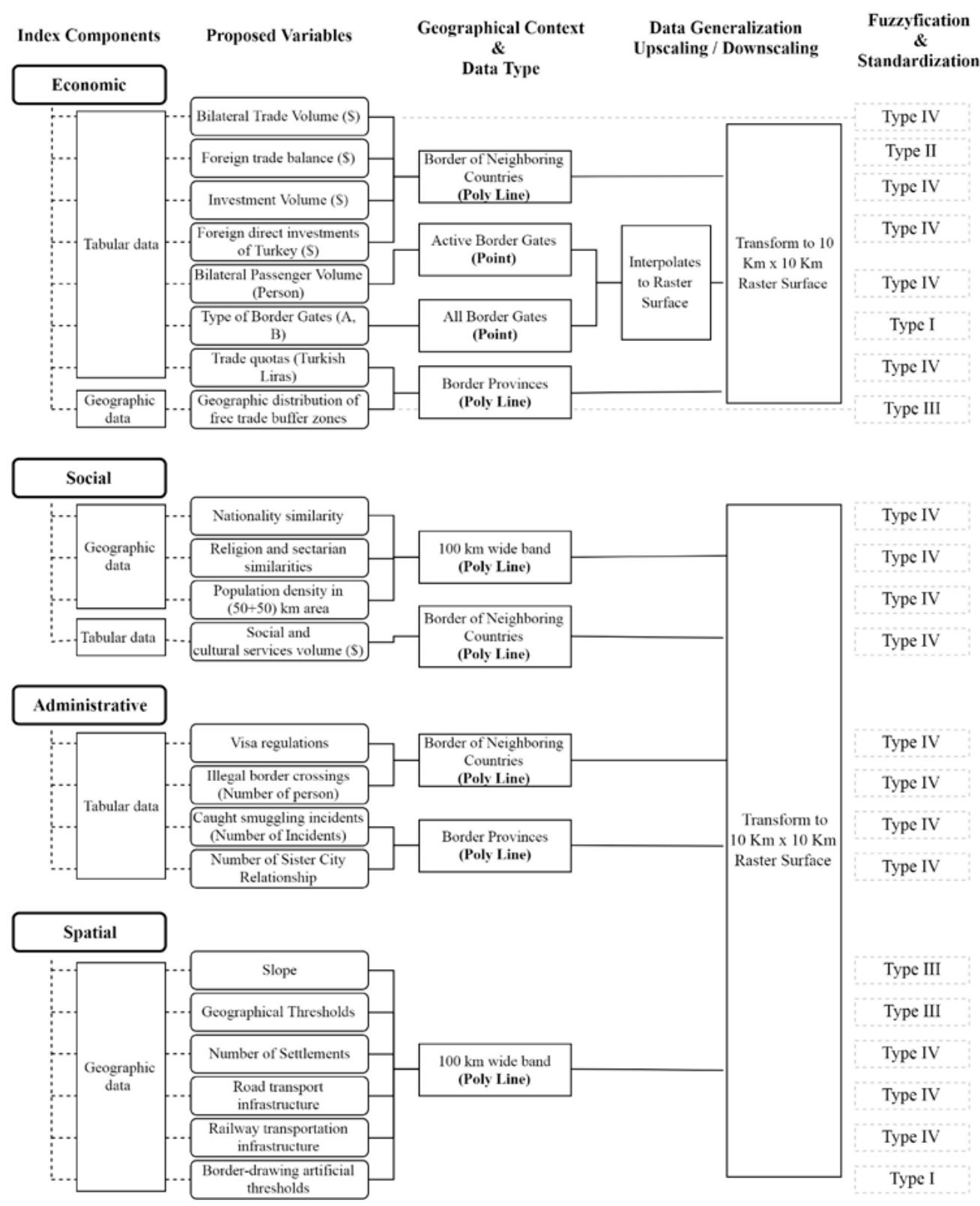

Figure 3. Subindex components and data preparation 


\section{Fuzzy Logic as a Method of Reclassifying and Standardizing Data}

By the mutual agreement of neighboring nation-states, border regions are separated by clear lines. However, due to the maintaining interaction among local inhabitants, they are transformed into areas with intermediate mobility values. Thus, they can be expressed with degrees of membership to a fuzzy set than with binary classification. However, studies on the measurement of the mobility at state borders have displayed definitive expressions based on expert opinions, but intermediate values are ignored (Dombi, 1990).

The proposed methodology in this study is associated with the fuzzy set theory that is used for quantifying the membership relationship of layers to specific sets, where a membership function defines the level of confidence, and whether an element belongs to the set or not (Zadeh, 1965). The fuzzy membership is generally used to reclassify and transform the input data into a scale of o to 1 indicating the membership strength of a set, based on the possibility of being a member of a set (Mesgari et al., 2008). Membership functions are important for reclassifying rasters since they affect the fuzzy inference system (Ross, 2010:89). In other words, membership functions are the representation of the degree of belonging to a fuzzy set by the type of functions. In theoretical and practical studies; triangular, sigmoid, sinusoid, trapezoid, Gaussian, bell and linear types of functions are determined to be the most suitable membership functions. These functions, which can be expressed by mathematical
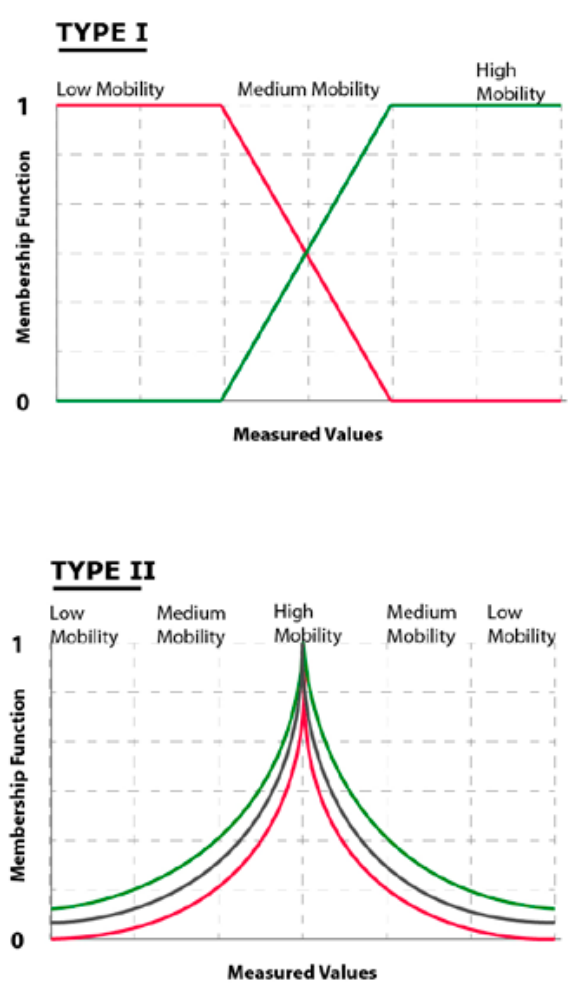

formulas and shapes, can be calculated with the parameters compatible with GIS software.

In this study ArcGIS spatial analyst tool is used for determining the appropriate membership function type. While reclassifying and transforming the raster data into a layer, firstly each data is reclassified and transformed into a o to 1 scale, identifying the possibility of belonging to an appropriate set. Then, within this framework, four types of membership functions are standardized by taking into account the data types and distributions related to the border mobility context (Figure 4). Here, each membership function transforms the data in a specific way to capture the interaction at the borderlands. The pixel values generated due to the data obtained by fuzzy logic are used as inputs. Thus, new pixel values are standardized according to the data type and distribution. With this fuzzification process, fuzzy cluster membership is performed for each data set. The values between o and 1 indicate the probability of fuzzy cluster membership, while a value of 1 indicates absolute membership. According to type, distribution, and standard deviation of the data, appropriate membership function is chosen to obtain the most appropriate transformation via different conversion parameters.

Type I is a fuzzy membership conversion method where expert-defined minimum values are assigned to o membership and maximum values are assigned to 1 membership by linearly. Thus, it transforms the input values linearly on o to 1 scale, with o being assigned to the lowest input value and 1 to the largest in-
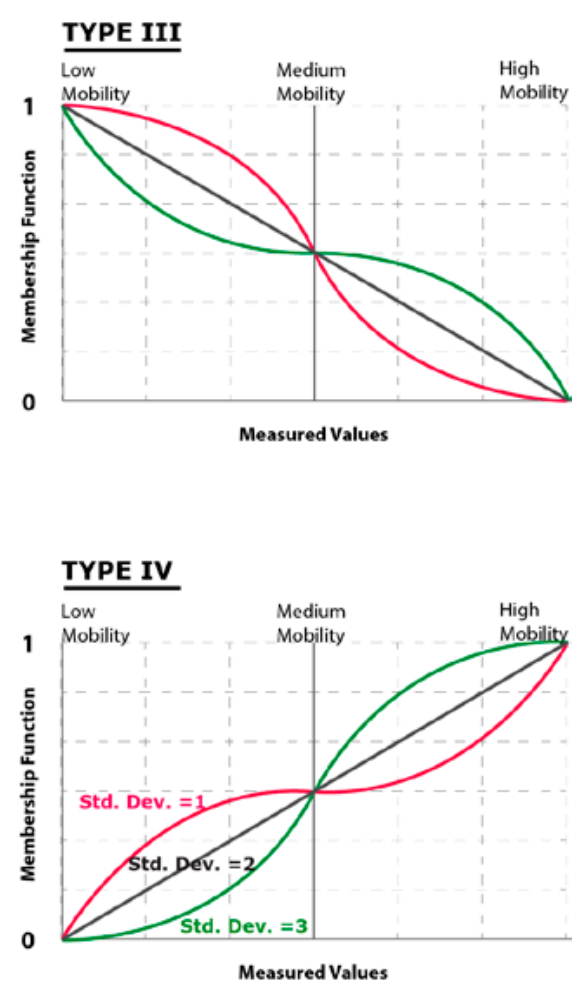

Figure 4. Types of Fuzzy Membership Functions 
put value. All the values between $o$ and 1 are assigned to base on a linear scale, with the larger input values closer to 1 , smaller values closer to o. Type I is applied to data sets where the measured values increase or decrease linearly. Type II is a fuzzy membership conversion method that transforms the original values into a normal distribution. The midpoint is assigned to be 1 , and the rest of the inputs decrease in both positive and negative directions moving away from the midpoint. In Type II maximum values in data distribution correspond to the middle of the distribution. Type III is a fuzzy membership function where small values are assigned to 1 , large values are assigned to o membership based on the arithmetic mean and standard deviation. Type III is used for the data types where the smaller values in the data set are more mobile. Type IV is the opposite of Type III where large values are assigned to 1 , small values to o membership based on the arithmetic mean and standard deviation. Contrary to Type III, in Type IV, the mobility level is high in large values but less in lower values.

In the standardization of multivariate data sets, generally boolean or expert methods are used. However, in this study, the fuzzy membership classification method was used for the standardization, before using map algebra operations. Using fuzzy set memberships is a significant step as it provides a very powerful tool for the standardization process (Jiang \& Eastman, 1999). Standardization through the use of fuzzy set membership provides the particular relationship between data distribution and decision-making that en- hances cross-border mobility precision. Thus, before the determination of border mobility, all the related data were transformed into a pixel-based structure for the spatial representation of the data. In this structure, the data was assigned to $10 x 10 \mathrm{~km}$ pixels. Thus, it was possible to perform pixel-based raster mathematical operations. The mobility of a relevant pixel value was evaluated in the GIS environment. 22 indicators were considered and mobility analysis was done by fuzzy membership classification (Type I, Type II, Type III and Type IV) by using weighting factors accommodating the relative importance of the cross-border mobility indicators (Figure 3).

The cross-border mobility model was obtained by combining the values of economic, social, administrative and spatial subindexes, by using simple additive weighted (SAW) method, which uses an averaging procedure based on the linear dependence of mobility from its constituting elements of economic, social, administrative and spatial. Each grid had values between $o$ and 1 for each variable of economic, social, administrative and spatial dimensions. After producing raw data acquisition and transformation to the appropriate spatial layers the overall model produced as the total of the economic, social, administrative and spatial permeability weights (Figure 5).

Continuous values for each economic, social, administrative and spatial raster layers representing the mobility and the boolean constraints were extracted from each grid resulting in a dataset consisting of approximately 343 individual grid for each of the var-

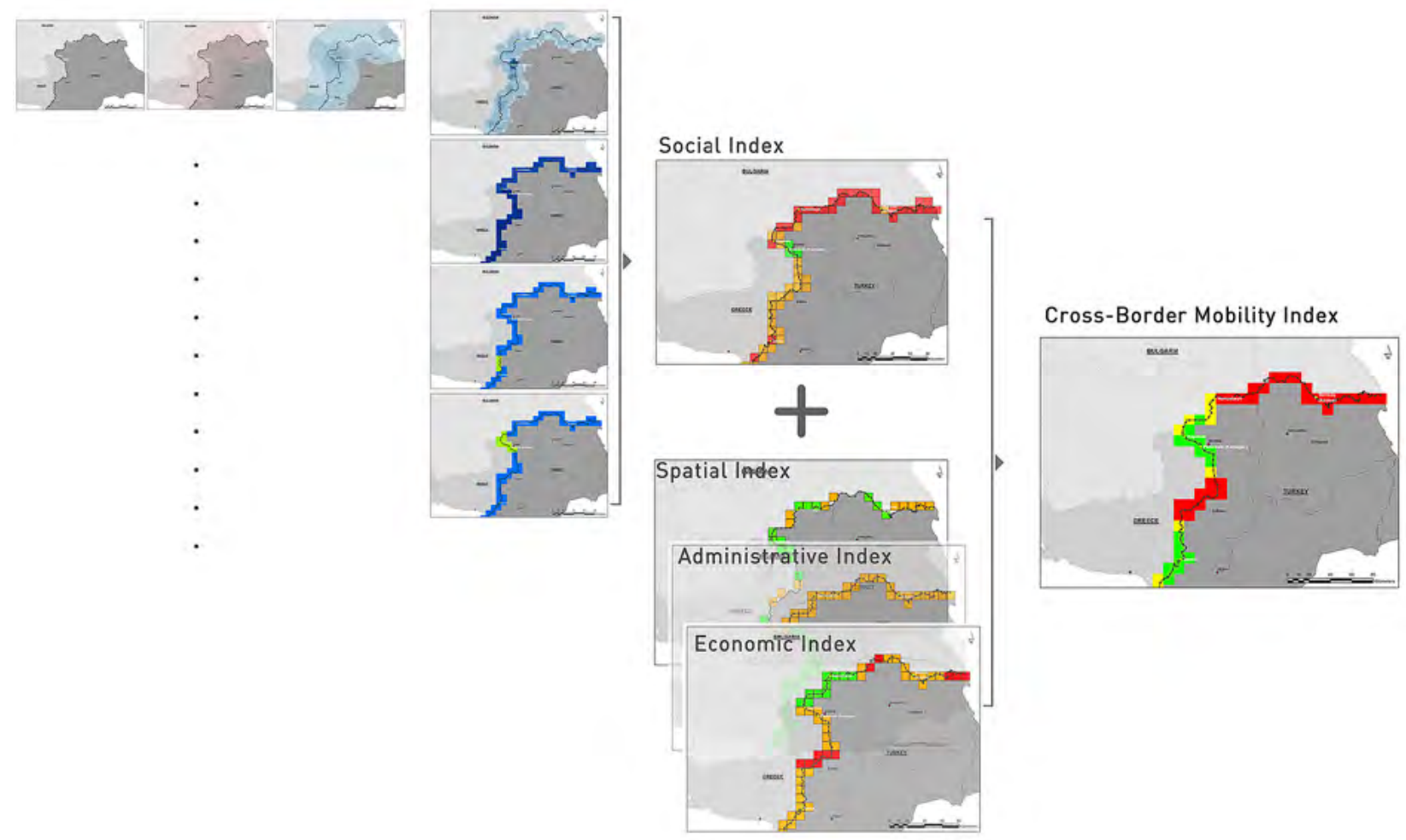

Figure 5. The process of obtaining multivariate socio-spatial cross-border mobility index 
iables. Thus mobility values were standardized to a common scale between o and 1 using fuzzy membership functions.

The effectiveness of the proposed model is based on the principle of fuzzy logic which uses prop- er membership function on each of the cross-border mobility variables instead of giving individual rank to them. Thus, fuzzy logic is used for reclassifying and transforming each border mobility layer to a common scale.

\section{Results \& Discussion}

The proposed cross-border mobility model provides an integrated measurement of mobility levels for borderlands, and it also provides separate information on mobility levels of economic, social, administrative and spatial aspects of the border region. In this framework, three cross-border mobility classification levels were defined and presented as low mobility, medium mobility and high mobility levels in order to simplify the results of the study. The standardized approach derived from the combined index methodology reveals cross-border mobility levels of state border regions in an economic, social, administrative and spatial manner.

Figure 6 demonstrates the economic, social, administrative and spatial cross-border mobility levels sepa-
For a detailed observation hypothetically for each grid, the highest level of the total cross-border mobility would be 1 , if the grid got the value of 1 from all the 22 variables.

However, in the analyzes, none of the $10 \times 10 \mathrm{~km}$ grids are found to be fully dynamic. Accordingly, the most dynamic grid gets a mobility value of 0.47 while the least get 0.04. The total cross-border mobility level by countries, the number of grids by the country borders and the average mobility values by countries are listed in Table 1. Accordingly, the Nakhchivan border has the highest cross-border mobility in terms of the average boundary mobility values. The lowest mobility level is in the Armenia border because of the inactive border crossing.

Table 1. Permeability rankings by country

\begin{tabular}{|l|c|c|c|}
\hline Country & $\begin{array}{c}\text { Total Cross-Border } \\
\text { Mobility Level }\end{array}$ & Number of Grids & Mean Mobility \\
\hline Nakhchivan & 0,38 & 1 & 0,38 \\
\hline Iran & 17,3 & 62 & 0,28 \\
\hline Greece & 6,33 & 23 & 0,28 \\
\hline Syria & 29,38 & 111 & 0,26 \\
\hline Georgia & 8,59 & 35 & 0,25 \\
\hline Iraq & 10,37 & 47 & 0,22 \\
\hline Bulgaria & 5,16 & 26 & 0,20 \\
\hline Armenia & 5,98 & 38 & 0,16 \\
\hline
\end{tabular}

rately and also gives the total cross-border mobility level of the Turkish borderlands. When the mobility maps are evaluated in three categories of low, medium and high mobility levels, it is seen that the mutually agreed border policies and the level of political relationships of the countries have a significant effect on cross-border mobility. The implemented foreign policies between countries differentiate the economic, social, administrative and spatial interaction levels.
When each axis of economic, social, administrative and spatial is considered separately, the highest cross-border mobility values are observed in social $(0,69)$, spatial $(0,64)$, economic $(0,60)$ and administrative $(0,54)$ axes respectively. In the covariance matrix, it is observed that there is an inverse relationship between spatial and social mobility levels (Table 2).

In areas with high spatial border mobility, social mobility indicator values tend to be low; in areas with

Table 2. Covariance matrix

\begin{tabular}{|l|c|c|c|c|}
\hline & Economic & Social & Administrative & Spatial \\
\hline Economic & $3,578190 \mathrm{e}-004$ & $2,066561 \mathrm{e}-006$ & $5,911725 \mathrm{e}-005$ & $1,515355 \mathrm{e}-005$ \\
\hline Social & $2,066561 \mathrm{e}-006$ & $5,988344 \mathrm{e}-004$ & $5,451609 \mathrm{e}-005$ & $-5,779285 \mathrm{e}-006$ \\
\hline Administrative & $5,911725 \mathrm{e}-005$ & $5,451609 \mathrm{e}-005$ & $5,189675 \mathrm{e}-004$ & $1,009887 \mathrm{e}-005$ \\
\hline Spatial & $1,515355 \mathrm{e}-005$ & $-5,779285 \mathrm{e}-006$ & $1,009887 \mathrm{e}-005$ & $3,979517 \mathrm{e}-005$ \\
\hline
\end{tabular}




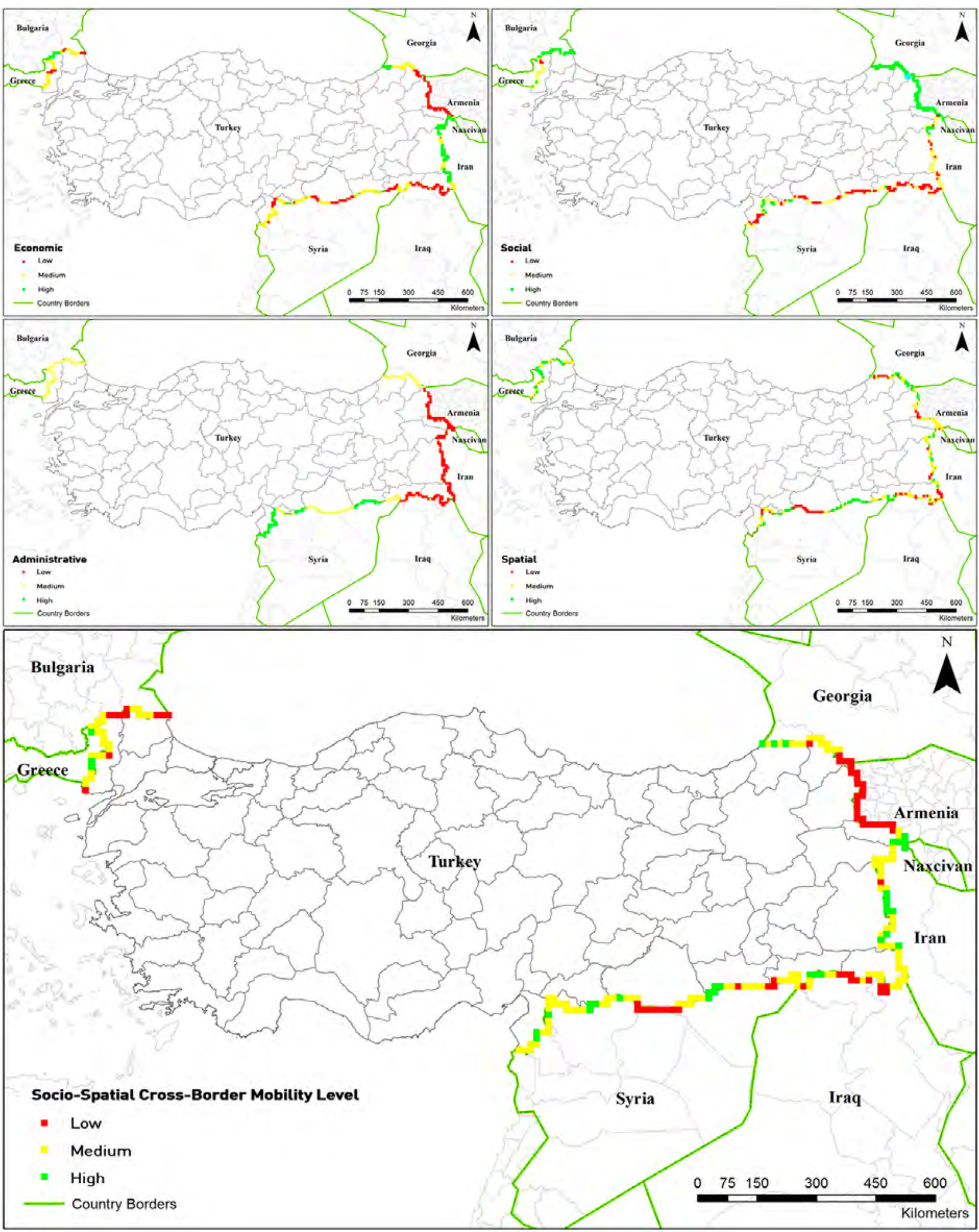

Figure 6. Cross-border mobility maps of the Turkish borderlands

high social mobility, spatial mobility values tend to be low. Examples of this inverse relationship are observed in the minefields adjacent to the border region with Syria that carry the characteristics of artificial barriers and low permeable areas. It is revealed that the minefields in the border regions do not directly affect social permeability in that region. On the contrary, these areas with low spatial mobility levels, have high social mobility levels.

In the correlation matrix, it is observed that the links among the whole axes are close to o, which indicates that there are no strong connections among the 
Table 3. Correlation matrix

\begin{tabular}{|l|c|c|c|c|}
\hline & Economic & Social & Administrative & Spatial \\
\hline Economic & 1,00000 & 0,00446 & 0,13719 & 0,12699 \\
\hline Social & 0,00446 & 1,00000 & 0,09779 & $-0,03744$ \\
\hline Administrative & 0,13719 & 0,09779 & 1,00000 & 0,07027 \\
\hline Spatial & 0,12699 & $-0,03744$ & 0,07027 & 1,00000 \\
\hline
\end{tabular}

axes. This makes it difficult to estimate the direction of one axis by looking at the direction of the other axis (Table 3).

While the cross-border mobility increases around the border gates, it decreases in borderlands where geographical thresholds are high, population density is low and transportation infrastructure is limited. On the other hand, the level of mobility around inactive border gates is not $\mathrm{o}$, which indicates that it is not the border gates only that increase or decrease the permeability values on their own, but other different socio-spatial relations that affect the cross-border mobility level.

In the total socio-spatial cross-border mobility, the regions with the lowest mobility are Iraq, Armenia and some parts of the Bulgarian border, mainly affected by spatial and administrative variables. The low mobility zone at Syrian border is located along the borderline with minefields, which appears as a spatial barrier for cross-border passages. On the other side, for Armenia border, the low levels of mobility is because of the inactive border gates and no border crossings because of the distant political relationships. When the axes are evaluated separately; for the economic axis, the lowest mobility is on Armenia border and the highest mobility is on Iran border around Kapıköy border gate. For the social axis, the lowest mobility is on Armenian and Georgian borders and the highest mobility is on Iraq border. For the administrative axis, the lowest mobility is on Iraq and Armenia border and the highest mobility is on Syrian border. According to spatial mobility indicators, it is difficult to generalize for the entire borderline where cross-border mobility is affected at the point level data. Consequently, these cross-border mobility levels help to understand the socio-economic and spatial interaction levels in different borderlands that give clues for the policymakers to develop foreign relationships accordingly.

\section{Conclusion}

This study reveals the cross-border mobility among neighboring countries, based on a multidimensional approach, including the economic, social, administrative and spatial relationships, rather than a onedimensional approach addressing solely the security issues. Thus, by using 22 different variables derived from theoretical and practical studies, four different types of sub-groups including economic, social, administrative and spatial components are achieved. Fuzzy membership functions are used in the normalization and standardization of the data sets. The concepts of fuzzy logic used in connection with the fuzziness contained by the border regions also correspond to the nature of the concept of cross-border mobility. Four different indices obtained from the analyses address different dimensions of border mobility, which is important in terms of allowing the decision makers to understand cross-border relationships in holistic manner.

The study makes two key contributions, both conceptually and methodologically. The conceptual contribution relates to propose cross-border mobility modeling and redefine the border mobility. It provides clues on how the socio-economic and socio-spa- tial dynamics can be treated without considering the borders of the countries, which politically/artificially divide the socio-spatial structure of the whole region. Besides, it clearly indicates which neighboring regions converge to each other or which of them diverge from each other along the borderline. Thus, it provides clues on how to see the borders and how to shape the regional and national level policies with the neighboring countries by considering the cross-border mobility of the border regions from a holistic perspective. This can help the establishment of cross-border multi-level governance policies including actors related to the border region.

The methodological contribution is related to measuring the cross-border mobility level by a more comprehensive and flexible set of indicators, instead of solely security-oriented indicators. It develops an innovative composite index methodology for a comprehensive understanding of socio-spatiality of border regions, which have various levels of interactions. The pillar of the methodological contribution is the spatialization of socioeconomic data by means of upscaling and downscaling, and the use of fuzzy logic in the reclassifying and standardizing of data. The index can be utilized as a model for 
other border regions to assess the cross-border mobility of the nation-state borders via the socio-spatial approach and fuzzy logic methods in GIS. It can be used for comparing the characteristics of border regions, or for estimating future developments following the same method and the same set of variables by using the computational procedures. The four different sub-indices obtained here demonstrate different dimensions of the border mobility separately. The integrated multivariate socio-spatial index, obtained from the total of the four indexes by using the SAW method is important in terms of providing an insight into the whole picture of cross-border relationships, which can be interpreted by nation-states on a country-by-country basis.

\section{Acknowledgment}

This study was developed as a part of the research titled "Socio-spatial interactions in the border regions: soft governance model for Turkey", which was supported by TUBITAK (Scientific and Technological Research Council of Turkey), SOBAG -114K887.

\section{References}

Anderson, J., \& O’Dowd, L. (1999). Borders, Border Regions and Territoriality: Contradictory Meanings, Changing Significance. Regional Studies, 33(7), 593604. https://doi.org/10.1080/00343409950078648

Anderson, J. (2001). Theorizing State Borders: Politics/ Economics and Democracy in Capitalism. CIBR Working Papers in Border Studies, Belfast.

Bandura, R., \& Campo, C. M. (2006). A Survey of Composite Indices Measuring Country Performance: UNDP/ODS Working Paper By Romina Bandura.

Cherchye, L., Moesen, W., Rogge, N., \& Van, T. (2006). An Introduction to "benefit of the doubt" composite indicators. Social Indicators Research, 82(1), 111145. https:// 10.1007/s11205-006-9029-7

Czaika, M., \& Neumayer E. (2017). Visa restrictions and economic globalization. Applied Geography, 84, 75-82, http://dx.doi.org/10.1016/j.apgeog.2017.04.011

Dodson, B. (2000). Porous Borders: Gender and Migration in Southern Africa. South African Geographical Journal, 82(1), 40-46. https://10.1080/03736245.2000.9713683

Dombi, J. (1990). Membership functions as an evaluation. Fuzzy Sets and Systems, 35, 1-21. https://doi. org/10.1016/0165-0114(90)90014-W

Evans, D., S. (2003). The Antitrust Economics of Multi-Sided Platform Markets. Yale Journal on Regulation, 20(2), 325-379

Hisakawa, N., Jankowski, P., \& Paulus, G. (2013). Mapping the porosity of international border to pedestrian traffic: a comparative data classification approach to a study of the border region in Austria, Italy, and Slovenia. Cartography and Geographic Information Science, 40(1), 18-27. https://10.1080/15230406.2013.762141

Izady, M., (2008a). Turkic Peoples and Languages of Middle East Vicinity http://gulf2000.colum-
bia.edu/images/maps/TurkicPeoplesLangs lg.png; (07.07.2019)

Izady, M., (2008b). Religious Composition of Middle East http://gulf2000.columbia.edu/images/maps/ Mid East Religion lg.png(07.07.2019).

Jiang J., \& Eastman, R. (1999). Application of fuzzy measures in multi-criteria evaluation in GIS. International Journal of Geographical Information Science, 14(2), 173-184.

Kolejka J., Wiesława Ź., Kateřina B., Stanisław C., Sylwia D., Karel K. , Tomáš K , Andrzej R., Waldemar, S., \& Jana Z. (2015). Permeability of Czech-Polish Border Using by Selected Criteria, Geographia Technica, 10(1), $51-65$.

Lun, G., Holzer, D., Tappeiner, G., \& Tappeiner U. (2006). The Stability of Rankings Derived From Composite Indicators: Analysis of The "Il Sole 24 Ore" Quality of Life Report. Social Indicators Research, 77(2), 307-331. https://10.1007/s11205-0054505-Z

Luo, F., Cao, G., Mulligan, K. \& Li, X. (2016). Explore spatiotemporal and demographic characteristics of human mobility via Twitter: A case study of Chicago, Applied Geography, 70, 11-25, https://doi. org/10.1016/j.apgeog.2016.03.001

Mazziotta, M., \& Pareto, A. (2013). Methods for Constructing Composite Indices: One For All or All For One?. Italian Review of Economics, Demography and Statistics, 67(2), 67-80.

Meirav, M. (2011). When Ethnicity and Religion Meet: Kinship Ties and Cross-Border Dynamics in the Afghan-Pakistani Conflict Zone. Nationalism and Ethnic Politics, 17(3), 257-275, https://doi.org/10.1080 $\lfloor 13537113.2011 .600101$

Mesgari, M. S., Pirmoradi, A., \& Fallahi, G., R. (2008). Implementation of Overlay Function Based on 
Fuzzy Logic in Spatial Decision Support System. World Applied Sciences Journal, 3 (1), 60-65.

Missbach, A. (2014). Doors and fences: Controlling Indonesia's porous borders and policing asylum seekers. Singapore Journal of Tropical Geography, 35(2), 228-244. https://10.1111/sjtg.12059

Nardo, M., Saisana, M., Saltelli, A., Tarantola, S., Hoffman, A., Giovannini, E. (2005).

Handbook on Constructing Composite Indicators: Methodology and User's Guide, Paris: OECD Statistics Working Paper, https://10.1787/533411815016

Nitsch, V. (2003). National borders and international trade: evidence from the European Union. Canadian journal of Economics, 33(4),1091-1105. https://doi. org/10.1111/0008-4085.00055

Obstfeld, M., \& Rogoff, K. (2000). The Six Major Puzzles in International Macroeconomics: Is There a Common Cause?. WP 7777, National Bureau of Economic Research: Cambridge. https://10.3386/w7777

O'Dowd, L. (2002). The Changing Significance of European Borders. Regional \& Federal Studies, 12(4), 13-36. https://10.1080/714004774

Popescu, G. (2006). Geopolitics of scale and cross border cooperation in Eastern Europe: the case of Romanian-Ukrainian-Moldovan borderlands, In J.
Scott (Eds.), EU Enlargement, Region Building and Shifting Borders of Inclusion and Exclusion, (pp. 3551) Aldershot: Ashgate.

Ross, T., J. (2010). Fuzzy logic with engineering applications. Singapore: Fabulous Printers Pte Ltd.

Sack, R. (1986). Human Territoriality: Its Theory and History. Cambridge: Cambridge University Press.

Santeramo, F. G. (2016). Methodological challenges in building composite indexes: Linking theory to practice. In J. Radojicic \& Dobrota (Eds.), Emerging Trends in the Development and Application of Composite Indicators. IGI Global.

Starr, H., \& Thomas, G. (2001). The Nature of Borders and Conflict: Revisiting Hypotheses on Territory and War. 2001 annual meeting of the APSA, American Political Science Association, San Francisco.

Stephenne, N., \& Pesaresi, M. (2006). Spatial Permeability Model at the European Union Land Border, EUR report 22332, Luxembourg: European Commission.

Zadeh, L. A. (1965). Fuzzy Sets, Information and Control, 8, 338-353

Zartman, I. W. (2010). Understanding Life in the Borderlands: Boundaries in Depth and in Motion. Athens, GA: University of Georgia Press. 